Roger Williams University

DOCS@RWU

2009

\title{
Technical efficiency estimates of Cherokee agriculture: A pre- and post-removal analysis
}

\author{
Matthew T. Gregg \\ RogerWilliams University, mgregg@rwu.edu
}

Follow this and additional works at: https://docs.rwu.edu/gsb_fp

Part of the Business Commons

\section{Recommended Citation}

Gregg, Matthew T. "Technical Efficiency Estimates of Cherokee Agriculture: A Pre- and Post-Removal Analysis." Journal of Socio-Economics, (3) 2009, pp. 18-29.

This Article is brought to you for free and open access by the Business at DOCS@RWU. It has been accepted for inclusion in Business Faculty Publications by an authorized administrator of DOCS@RWU. For more information, please contact mwu@rwu.edu. 


\title{
Technical efficiency estimates of Cherokee agriculture: A pre- and post-removal analysis
}

\author{
Matthew T. Gregg* \\ Gabelli School of Business, Roger Williams University, Bristol, RI 02809, United States
}

\section{A R T I C L E I N F O}

\section{Article history:}

Received 8 October 2006

Received in revised form 26 March 2009

Accepted 26 March 2009

\section{JEL classification:}

N11

N31

N91

Keywords:

Technical efficiency

Cherokee Indians

Agriculture

DEA

\begin{abstract}
A B S T R A C T
Although there is a large literature on the pre-removal Cherokee acculturation during the early nineteenth century there are no estimates of the technical efficiency of Cherokee agriculture. In this paper two sets of nineteenth century farming data on Cherokee households are used to estimate Shephard output distance functions and to model the determinants of Cherokee technical efficiency. Controlling for farm size, spatial heterogeneity, market orientation, and experience, technical efficiency was between $7 \%$ and $9 \%$ greater in mixed-blooded households than in full-blooded households. However, using pooled time series data of post-removal Cherokee farm households in North Carolina, Cherokee technical efficiency ranged from $0 \%$ to $4 \%$ less than the efficiency of their neighboring white farmers.
\end{abstract}

(ㄷ) 2009 Elsevier Inc. All rights reserved.

\section{Introduction}

The objective of this paper is to answer one of the most important economic issues in American Indian history: how productive were Cherokee Indian farmers during the nineteenth century? As Indian removal's cause célèbre, Cherokee economic and agrarian progress was widely debated. This political debate focussed on conjectures regarding the productivity differentials between Cherokee and white farmers and between mixed-blooded and full-blooded Cherokee farm households. To date, Dunaway (1997) and Wishart (1995) have used simple partial productivity measures to promote the level of agrarian process by the Cherokees as a whole. In this paper, I exploit two detailed household-level data sets on nineteenth century Cherokee farm output to estimate the technical efficiency of individual Cherokee farmers. These estimates are then regressed on a variety of exogenous variables to identify the ceteris paribus impact of inter- and intra-ethnic differences on agricultural productivity.

The productivity of Cherokee agriculture before removal was largely characterized using racial constructs. While politicians like Andrew Jackson, Lewis Cass, and Wilson Lumpkin used the language of race for their own ends, historians such as Champagne

\footnotetext{
* Tel.: +1 401254 3160; fax: +1 4012543545.

E-mail address: mgregg@rwu.edu.
}

(1992), McLoughlin (1986), Malone (1956), and Sturm (2002) all emphasize racial hierarchy as an important factor of political, social, and economic behavior in Cherokee history. ${ }^{1}$ Regarding Cherokee agriculture, McLoughlin and Conser (1977, 1984) and Wilms (1978) suggest that full-blooded Cherokees achieved lower yields than mixed-blooded Cherokees. ${ }^{2}$ Unlike nineteenth-century claims, McLoughlin and Conser (1984, p. 223) use rational, rather than essentialist, terms to explain the variation in productivity:

The smaller size of its [full-blooded North Carolina Cherokee] farms and the smaller yield of its crops (particularly its low wheat yield) are evidence both of the mountainous area, the poor soil, the lack of money to invest in slaves or plows, and con-

\footnotetext{
${ }^{1}$ For example, Cass (1830) wrote that "[i]ndividuals among the Cherokees have acquired property ... [a]nd we have as little doubt, that this change of opinion and condition is confined, in a great measure, to some of the half-breeds and their immediate connexions." Even American Board missionaries, who lived among the Cherokees prior to removal and attempted to emphasize the view of tribal-wide assimilation, often used similar language: "The intermixture of white people with the Indians has undoubtedly been a considerable cause of the civilization of the latter" (qtd. in Perdue, 2004).

2 Mixed-blooded Cherokees are children from a Cherokee-white union. Scholars have used metis or mestizo to divorce these groupings from the racial interpretations developed in the early nineteenth century. This paper, like Robertson's (2002) recent work on Oglala Lakota land use, adopts the term mixed-blood because it is stil widely used in contemporary Indian communities and is more historically accurate than implying a French or Spanish connection.
} 
sequently of the general poverty of the Cherokees in this region. Possibly isolation from white settlements, adherence to traditional life-style, and deliberate resistance to change contributed to these differences.

The adoption of an overlooked household-level Cherokee census taken in 1835 allows for at least two contributions to this literature. First, a more complete measure of farm productivity, an output-oriented measure of technical efficiency, can be estimated by incorporating multiple farm outputs and multiple factors of production. In the context of economic theory, Farrell (1957) lists managerial characteristics as the principal factors that influence productive efficiency. Therefore, if full-blooded households decided to use dated farming practices, then economic theory would suggest that full-blooded "traditionalists" would be less technically efficient than mixed-blooded "progressives." Second, the role of cultural persistence on efficiency can be isolated once control variables like farm size, soil quality, market orientation, and farm experience are included in the empirical model. Recent developments by Simar and Wilson (2007) provide a method to measure bias-corrected technical efficiency using non-parametric techniques and to model the determinants of those efficiency scores.

Within the larger ethnohistorical literature, this study introduces a quantitative analysis into the recent debate over the role of race on culture in Southeastern Indian communities. Relying on anthropological theories and mainly eighteenth-century observations, Perdue $(2003,2004)$ emphasizes how white men were strategically chosen and adopted into the nation on Cherokee terms. Given the Cherokee matrilineal kinship system, white males would have had a limited role within the household, since maternal uncles provided more influence on children. This kinship system also implies that only members of a Cherokee clan were considered Cherokee. Thus, the concept of racial hybridity may have been unrelated to Cherokee identity. Even when adopting racial categories, Perdue (2004) maintains that a closer look at acculturation reveals that "many 'full bloods', as well as 'mixed bloods', welcomed aspects of the U.S. 'civilization' program." 3 The fluidity within intra-ethnic groups is readily apparent when analyzing the leaders of the two factions over Cherokee removal. ${ }^{4}$ Major Ridge, a full-blooded Cherokee, led members of the mainly mixed-blooded, pro-removal Treaty Party, while the Anti-removal Party was comprised mostly of full-blooded Cherokees and was organized under the leadership of Principal Chief John Ross, who was one-eighth Cherokee.

On the other hand, Saunt et al. (2006) still maintain the traditional viewpoint that race was "essential to formations of power and resistance ... [and] must be a central component of ethnohistorical analysis." Regarding economic behavior, historians have long maintained that the Cherokees who attempted to possess the trappings of a "civilized" life by purchasing African slaves, using Euro-American farming practices, and actively accumulating wealth were children from a European-Indian union. The conventional viewpoint also suggests that full-blooded Cherokees rejected many aspects of "civilization" by refusing to restructure gender roles within their traditionally female-oriented agricultural system.

\footnotetext{
${ }^{3}$ Henry Knox, the Secretary of War during Washington's administration, devised the first federal Indian policy of "civilization." The policy stated that treaty stipulations would furnish Indians with farm implements, livestock, and residential Indian agents to lead them in the adoption of Euro-American farming practices. The 1791 Treaty of Holston was the first Cherokee land cession to contain these features. See Royce (1975) for a list of nineteenth-century Cherokee treaty stipulations.

${ }^{4}$ Historians also emphasize that wealth accumulation and world views varied within these groups. For example, Sturm (2002, p. 68) emphasizes that "these categories of identity were social constructions that had only a loose correspondence with racial ancestry, since Cherokees with white ancestry could also be poor, nonChristian or against black slavery."
}

These interpretations suggest that the importance of kinship within the Cherokee Nation declined substantially prior to removal.

Given this debate, the impact of race on the adoption of the "civilization" program, which would have been manifested in higher technical efficiency measures, is unclear. Fortunately, a limited but rare data set on Cherokee farm households enumerated in 1835 allows for the estimation and comparison of technical efficiency at the household level. McLoughlin and Conser $(1977,1984)$ use this data to find associations between racial hierarchy and acculturation (defined in their study as the acquisition of economic and linguistic skills). In particular, they show that mixed-blooded families held more slaves and contained more readers of English than full-blooded households, while full-blooded households held more farms and more skilled members (i.e., adult farmers and mechanics). ${ }^{5}$ Yet, if the main historical issue over Cherokee acculturation pertains to the implementation of Euro-American farm practices, then measuring technical efficiency, which reflects the ability to produce maximal output given the input usage, is the more appropriate metric than their acculturation statistics. Also, as suggested in McLoughlin and Conser (1977), if members of the small, mixed-blooded elite planter class were outliers, then mean crop yields would be sensitive to the inclusion of these households. This issue will be considered in the pre-removal results section.

The second main issue regarding Cherokee productivity is its relative efficiency when compared to their white neighbors. As mentioned earlier, the performance of Cherokee Indian farming became the most important criterion in the political battle for maintaining their remaining ancestral land. Removal advocates believed that the right to cultivate land was reserved to "civilized" men rather than to "savages" who used the land primarily to hunt (see de Vattel, 1758 for the earliest development of this philosophy). Given their constituents' large demand for land disposal, politicians strongly believed that Indians were not using land up to its potential (Perdue and Green, 2007, p. 14). In particular, President Andrew Jackson used this rhetoric to promote his plan to remove the Cherokees and other Indian tribes west of the Mississippi River. According to Jackson (1833),

They have neither the intelligence, the industry, the moral habits, nor the desire of improvement which are essential to any favorable change in their condition. Established in the midst of another and a superior race, and without appreciating the causes of their inferiority or seeking to control them, they must neces-

sarily yield to the force of circumstances and ere long disappear.

Pre-removal comparative farming data simply do not exist. The earliest household-level data on U.S. agriculture are located in the 1850 and 1860 manuscript censuses. Fortunately, the Cherokees living in Haywood and then Jackson County, North Carolina who avoided removal were enumerated alongside their white neighbors in the 1850 and 1860 population and agricultural manuscript censuses. By sampling white and Cherokee farm households from these two counties in 1850 and 1860, a richer database can be used to compute technical efficiency measures on both types of farms. The advantage of this data set is that the estimation problems from the data limitations in the 1835 Cherokee census can be resolved.

\section{Methodology}

The methodology used here largely follows from Färe et al. (1994) and Simar and Wilson (2007). When multiple inputs and outputs are used in production, the underlying production process and productive efficiency can be described with distance functions

\footnotetext{
5 Thornton (1990) also uses the idiom of race to show the positive correlation between white ancestry and the number of slaves.
} 
(Shephard, 1970). Given the existence of a best practice production frontier, an output distance function shows the amount actual output falls short of what can be feasibly produced given some level of inputs. The output distance function of a multiple-output and multiple-input production technology can be expressed as

$D_{o}(x, y)=\min \{\theta: y / \theta \in P(x)\}$

where $\theta$ is a measure reflecting the amount by which the observed vector of outputs that can be radially increased and still remain feasible for a given input vector; and $P(x)$ is the set of feasible pairs of outputs $(y)$ and inputs $(x)$, where both $x$ and $y$ are vectors. Under the typical assumptions, $D_{0}(x, y)$ is nonincreasing in $x$, and nondecreasing, homogenous of degree one, and convex in $\mathrm{y}$. If the household is fully efficient, then $D_{0}(x, y)=1 .{ }^{6}$ As the distance between the observed vectors of outputs and the frontier increases, $D_{0}(x, y)$ decreases. Therefore, $D_{0}(x, y)$ lies between zero and one.

This distance function can be estimated by using a linear programming method called Data Envelopment Analysis (DEA). This non-parametric approach builds a production frontier that envelopes the data and measures the distance from observed output to the best practice frontier. The key advantages of DEA over the parametric stochastic frontier approach is that DEA can easily accommodate multiple outputs and zero values for some observations. ${ }^{7}$ This approach also does not require the adoption of market prices to aggregate output, which can conflate revenue efficiency with technical efficiency (David and Temin, 1979).

With $I$ households, $M$ outputs, and $N$ inputs, DEA computes technical efficiency measures by solving the following linear programming problem under the assumption of constant returns to scale:

$$
\begin{aligned}
& D_{o}(x, y)=\left[\max _{\left\{\theta, z_{i}\right\}} \theta\right]^{-1} \\
& \text { s.t. } \quad \theta_{k} y_{m i} \leq \sum_{i=1}^{I} z_{k} y_{m i}, \quad m=1, \ldots, M \\
& \sum_{i=1}^{I} z_{i} x_{n i} \leq x_{n i}, \quad n=1, \ldots, N \\
& z_{i} \geq 0, \quad i=1, \ldots, I
\end{aligned}
$$

where $z_{i}$ reflects the intensity weights used to compute the piecewise production frontier (Färe et al., 1994). Since this problem is solved for each observation, $\theta$ will reflect the efficiency score for each household. The technical efficiency term ranges from zero to one as one reflects $100 \%$ technical efficient.

In the second stage, these DEA efficiency scores are regressed on a set of explanatory variables. However, as illustrated by Simar and Wilson (2007), statistical inference from this second-stage regression is invalid since the DEA scores are by construction serially correlated. They do prove that consistent inference can be obtained by bootstrapping the DEA scores, correcting for sampling bias, and using maximum likelihood to estimate a truncated regression model of the DEA scores on a set of variables. Bootstrapping the efficiency measures simulates the underlying sampling distribution and the bias is subtracted from the original DEA score for each household to generate a bias-corrected technical efficiency measure. For this study, I follow Simar and Wilson's (2007) first algorithm.

\footnotetext{
${ }^{6}$ If the vector of output for the $i$ th household, $y_{i}$, was located on the frontier, $y_{i}^{*}=\theta_{i}^{\prime} y_{i}$, then $y_{i}=\theta_{i}^{\prime} y_{i}$. In this case, for the $i$ th observation, $\theta_{i}=\left(y_{i}\right) /\left(y_{i}\right)$ or $\theta_{i}=1$. Therefore, the technical efficiency is equal to one when the vector of output cannot be radially expanded.

${ }^{7}$ Flexible functional forms such as generalized Leontief, CES, and generalized McFadden all failed to hold regular conditions as they computed negative and nondiminishing marginal products. Data transformations, e.g. setting $\ln (0)=0$, are not used since they reorder the observations in the range of $[0,1]$.
}

Although the term efficiency is used through the paper, deviations from the frontier may not in fact be "sub-optimal." Unobserved constraints may lead some to optimally choose input and output quantities that appear to be inefficient. The measurements of efficiency may simply reflect differences in constraints as some households may farm on poorer soil, contain less farm experience, or suffer more from market imperfections. The goal is to control for these multiple factors of inefficiency in order to isolate the conditional impact of racial hierarchy on productivity.

\section{The relative efficiency of Cherokee farming}

\subsection{Pre-removal data}

The pre-removal data for this study come from a census of Cherokee farm households in 1835 collected by the War Department, who was in charge of Cherokee emigration throughout the 1820 s and 1830s. The location of each household in the census was identified by the state of residence (i.e., Alabama, Georgia, North Carolina, or Tennessee), county within the state, and place-name within the county. Assisted by Cherokee interpreters, the census takers enumerated 36 different characteristics on 2670 households. The category headings included information on the size of the household, number of slaves, various agricultural inputs and outputs, other wealth information like number of (grist and saw) mills and ferryboats, literacy information, and the racial characteristics of the household. ${ }^{8}$

For the DEA analysis, two output and four input variables are used. Only bushels of corn and wheat grown were listed in the census. According to the census, $89 \%$ of the households grew corn while only $2 \%$ grew wheat. Other traditional crops such as beans, squash, peas, and potatoes were unfortunately omitted from the census (Hudson, 1976). However, the heavy reliance on corn within this Southern region after removal is shown in Weiman's (1987) work on Upcountry farmers. ${ }^{9}$ Crop diversification estimates can be gleaned from the post-removal North Carolina Cherokee data on corn, peas, beans, and potato production. On North Carolina Cherokee farms that were roughly the same size as 1835 Cherokee farms, $95 \%$ of total crop output comprised solely of corn bushels. The pre-removal Cherokees were not self-sufficient, however, as Goodwin (1977), Perry (1974), and White (1975) all emphasize the reliance on "wild" foods in Cherokee diets. While the precise degree of diversification is unknown, these comparisons do suggest that it may have been limited. The chief limitation of these output variables is that it may bias the efficiency gains of larger slaveholders. ${ }^{10}$

The household labor variable treats adult males (over the age of 18), adult females (over the age of 16), and married whites (mainly males) as equals while counting half of the males under

\footnotetext{
${ }^{8}$ Regarding the accuracy of the data, there was only one account of a North Carolina census taker running into difficulty with data collection. However, Principal Chief John Ross helped thwart any backlash with an open letter read at a regional council meeting. In the letter, John Ross wrote, "I do not ask it as a favor but claim it as a right to proceed in taking your numbers and will view your refusal as a direct declaration that you have no friendship for the Government of the United States" (qtd. in Litton, 1940). There was no documented evidence of interference after this date.

${ }^{9}$ Weiman (1987) shows that on Upcountry farms that contained at least 500 improved acres in 1860 , corn still comprised $77 \%$ of total crop output.

10 Cotton would be the chief omitted variable on large plantations. McLoughlin (1974) cites a letter from John Ridge, son of Major Ridge, to Albert Gallatin, Secretary of the Treasury under Jefferson's administration, where Ridge claims that "cotton is generally raised for domestic consumption and a few have grown it for market and have realized very good profits." Slaveholding households did account for only $7.8 \%$ of the total Cherokee households in 1835.
} 
the age of 18 and females under the age of 16 . These demarcations were determined by the limitations of the census. However, the assumed participation rate for young males is equivalent to the four-state average during the antebellum period (Weiss, 1992). A Cherokee household averaged six members while $7 \%$ of those households also held a married white. Off-the-farm work was limited as only $2 \%$ of the households generated income from operating either a mill or a ferryboat. This suggests that the substitution between farm work and other work-related activities was undoubtedly minimal by the third decade of the nineteenth century. Lastly, adult females are added to the labor variable because historical evidence suggests that some females still kept their role as chief cultivator of the household during the "civilization" program. ${ }^{11}$

The slave variable assumes equal roles for male and female slaves as age differences were not listed in the census. In their analyzes of Cherokee slavery, Perdue (1979) and Halliburton (1977) do not distinguish work roles by gender. Gang labor systems were not employed by slaveholders in the Cherokee Nation as only $10 \%$ of the slaveholders held over 15 slaves.

The land variable is defined as total acres cultivated. Rather than constructing a variable reflecting land solely devoted to corn and wheat, this variable is left unaltered. Weiman's (1987) study on antebellum Upcoming farming suggests that crop diversification and farm size were unrelated: farms averaging 1-50 acres held a corn share of $77.9 \%$, while the largest farms in his sample (over 500 acres) held a corn share of $77.4 \%$. Among Cherokee households in 1835 , there very little correlation between farm size and corn yields. $^{12}$

Another issue with the land variable is accounting for soil quality. The soil quality index constructed here is based around Field's (1988) suggestion. Specifically, households were split into groups defined by three county-level soil types listed in Hilgard (1884). Each category was further divided based on a household's proximity to a waterway as defined in the 1835 census. The soil quality index is computed by comparing the output per acre within these six categories, using the category with the highest average yield as the base category. Most technical efficiency studies include soil quality and other environmental variables in the second-stage regressions. Likewise, soil quality in this study is assumed to directly affect efficiency and is thus incorporated into the second stage.

Finally, the total number of buildings is included as a proxy for the physical capital input since the value of farming implements and livestock were not enumerated. These buildings would have reflected the number of dwellings, kitchens, slave quarters, corn cribs, smokehouses, outhouses, and workshops contained on a farm. A farmer who invested heavily in structures probably also invested in farm implements and other capital inputs. In practice, the inclusion of this variable did not greatly alter the efficiency measures. ${ }^{13}$

After removing unusable observations (i.e., households with no acres cultivated and no corn produced), 2344 slaveholding and non-slaveholding Cherokee families are used to estimate household-level technical efficiency. Eventually all of the data contained in the census is incorporated once the observations are aggregated into communities.

\footnotetext{
11 Traditionally, Cherokee men helped only with breaking soil and harvesting crops See Hatley (1988) for an overview of the continued role in women in agriculture during this period.

${ }^{12}$ The sample correlation coefficient between corn yields and acres cultivated is -0.061 and is statistically insignificant at common significance levels.

13 The sample correlation coefficient between the technical efficiency computed with and without this capital input proxy is 0.963 and is significant at the $1 \%$ level.
}

Table 1

Explanatory variables of pre-removal technical efficiency.

\begin{tabular}{|c|c|}
\hline Variable & Definition \\
\hline \multicolumn{2}{|l|}{ Intra-ethnic categories } \\
\hline Full-blood share & $\%$ of household comprising of full-blooded members. \\
\hline All mixed ${ }^{a}$ & $\begin{array}{l}1 \text { if entire family are mixed-blooded Cherokees, } 0 \\
\text { otherwise. }\end{array}$ \\
\hline Partially mixed & $\begin{array}{l}1 \text { if family contains at least one mixed blood but not all, } 0 \\
\text { otherwise. }\end{array}$ \\
\hline Married white ${ }^{b}$ & $\begin{array}{l}1 \text { if family contains at least one married white member, } 0 \\
\text { otherwise. }\end{array}$ \\
\hline \multicolumn{2}{|l|}{ Farm size } \\
\hline Land & Acres cultivated. \\
\hline \multicolumn{2}{|l|}{ Spatial heterogeneity } \\
\hline Soil quality index ${ }^{c}$ & Soil quality index. \\
\hline \multicolumn{2}{|l|}{ Market orientation } \\
\hline Market access & $\begin{array}{l}\text { Share of total corn and wheat output that was sold in local } \\
\text { markets. }\end{array}$ \\
\hline English readers & $\begin{array}{l}\text { Share of Cherokee household comprising of English } \\
\text { readers. }\end{array}$ \\
\hline \multicolumn{2}{|l|}{ Farm experience } \\
\hline Age & Share of household consisting of farmers over the age of 18 . \\
\hline
\end{tabular}

a A mixed-blood household is defined as a family containing at least one $1 / 4$ Cherokee, $1 / 2$ Cherokee, mixed-black, or mixed-Catawba. Families with married whites are omitted from this category.

b This category was not gendered; however, prior population counts show that over $70 \%$ of these whites were males.

c This index was computed after Field's (1988) suggestion. The households were split into groups defined by three county-level soil types (Hilgard, 1884) and then further decomposed into groups determined by location from a river. Then the index was computed by comparing output per acre within these six categories.

\subsection{Pre-removal results}

The definitions of the explanatory variables used in this stage are located in Table 1. Intra-ethnic groups are eventually disaggregated into four categories: households with all mixed-blooded Cherokees but no married whites (221 observations); members with some mixed- and full-blooded members (261 observations); households that contained a married white (158 observations); and households with all full-blooded members (1704 observations). ${ }^{14}$

Once the technical efficiency measures are computed using the framework discussed in Section 2, truncated regression models of the bias-corrected efficiency scores on a set of variables are estimated using maximum likelihood and the results are located Table 2. Each regression controls for heteroskedasticity by implementing the White method. Unless noted, each estimates in Table 2 is significant at the $1 \%$ level.

The unconditional regression model (1) implies that a $10 \%$ increase in the share of full bloods within a household decreased technical efficiency by $1.7 \%$. This initial finding is augmented in the next five regressions by incorporating other factors (farm size, soil quality, market orientation, and experience) in a step-wise fashion. Each coefficient, except for the share of English readers, is significant at the $1 \%$ level. Several notes need to be mentioned before discussing the intra-ethnic variables. First, the inverse-U relationship between efficiency and farm size and the efficiency gains from market access and farming experiences are consistent with most micro-level agricultural studies. ${ }^{15}$ Also, the impact of acres cul-

\footnotetext{
${ }^{14}$ Using the census definitions, a mixed-blooded Cherokee is defined as either $\frac{1}{2}$ Cherokee, $\frac{1}{4}$ Cherokee, mixed-black, or mixed-Catawba. Less than $1 \%$ of the Cherokee population in 1835 was mixed-black or mixed-Catawba.

${ }_{15}$ Chayanov (1966) and Sen (1966) are the classic works on the inverse relationship between farm size and (labor) productivity. Also, see Helfand and Levine (2004) and Sherlund et al. (2002) for two recent examples of the positive influence of market access and experience on efficiency.
} 
Table 2

The determinants of pre-removal technical efficiency.

\begin{tabular}{|c|c|c|c|c|c|c|}
\hline Variable & (1) & $(2)$ & (3) & $(4)$ & $(5)$ & (6) \\
\hline \multicolumn{7}{|c|}{ Intra-ethnic categories } \\
\hline Full-blood share & -0.168 & -0.119 & & -0.098 & -0.084 & -0.091 \\
\hline All mixed-blood & & & 0.109 & & & \\
\hline Partial mixed & & & 0.049 & & & \\
\hline Married whites & & & 0.113 & & & \\
\hline \multicolumn{7}{|l|}{ Farm size } \\
\hline Land & & 0.004 & 0.004 & 0.004 & 0.003 & 0.003 \\
\hline Land $^{2}$ & & -0.001 & -0.001 & -0.001 & -0.001 & -0.001 \\
\hline \multicolumn{7}{|l|}{ Spatial heterogeneity } \\
\hline Soil quality index & & & & 0.079 & 0.067 & 0.068 \\
\hline \multicolumn{7}{|l|}{ Market orientation } \\
\hline Market access & & & & & 0.139 & 0.129 \\
\hline English readers & & & & & $0.044^{\mathrm{a}}$ & $0.025^{a}$ \\
\hline \multicolumn{7}{|l|}{ Farm experience } \\
\hline Age & & & & & & 0.129 \\
\hline Log-likelihood & 2211.57 & 2247.66 & 2245.89 & 2271.79 & 2286.40 & 2296.37 \\
\hline$\chi^{2}$-Statistic & 110.62 & 176.23 & 165.62 & 183.52 & 204.20 & 206.60 \\
\hline
\end{tabular}

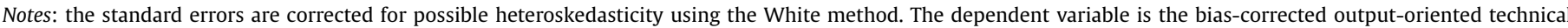
efficiency. All coefficients are statistically significant at the $1 \%$ level unless noted.

a Not statistically significant at the $10 \%$ level.

tivated, soil quality, and market access on efficiency do not vary across regression specifications. Among these variables, market access has the largest impact on efficiency followed by farm experience and soil quality. The coefficient in the last regression implies that a $10 \%$ increase in the share of farmers within the household would have increased technical efficiency by $1.29 \%$.

Regarding the intra-ethnic variables, the estimated coefficient on the full-blood share variable appears to be insensitive to model specifications. For example, controlling for farm size and soil quality, the technical efficiency of full-blooded households was between $9.8 \%$ and $11.9 \%$ less than the efficiency of mixed-blooded households. Once market orientation and farm experience are included, the superior efficiency gains by mixedblooded households is still positive but ranged between $8.4 \%$ and $9.1 \%$. Within all types of mixed-blooded households, model (3) reveals that the largest productivity premium occurred in households that contains a married white followed by households with all mixed-blooded members. In sum, while other environmental variables weakened the role of race on productivity, there was a consistent ceteris paribus impact of intra-racial differences on technical efficiency. These estimates suggest that cultural persistence, defined as foregone output, can be associated with full-blooded households.

A number of variations to these models are estimated to determine the robustness of these findings. First, since DEA is sensitive to outliers, 125 of the most efficient observations (5.3\% of the sample) were omitted, and the DEA approach was re-run and the determinants re-estimated using the method described in Section 2. The findings are located in Table 3. The statistical and economic significance of the coefficients on married white households, all mixed-blooded households, partially-mixed households, and fullblood share remained. After omitting the most efficient producers, the technical efficiency on mixed-blooded households ranged from $7.6 \%$ to $11.0 \%$ above the efficiency of full-blooded households.

Second, the slaveholding households are omitted from the sample to determine if the shape of the frontier drastically changed.

Table 3

Truncated regression results-omitting 125 most efficient observation.

\begin{tabular}{|c|c|c|c|c|c|c|}
\hline Variable & $(1)$ & $(2)$ & (3) & $(4)$ & (5) & (6) \\
\hline \multicolumn{7}{|c|}{ Intra-ethnic categories } \\
\hline Full-blood share & -0.144 & -0.110 & & -0.089 & -0.076 & -0.082 \\
\hline All mixed-blood & & & 0.102 & & & \\
\hline Partial mixed & & & 0.045 & & & \\
\hline Married whites & & & 0.101 & & & \\
\hline \multicolumn{7}{|l|}{ Farm size } \\
\hline Land & & 0.003 & 0.003 & 0.003 & 0.003 & 0.003 \\
\hline Land $^{2}$ & & -0.001 & -0.001 & -0.001 & -0.001 & -0.001 \\
\hline \multicolumn{7}{|l|}{ Spatial heterogeneity } \\
\hline Soil quality index & & & & 0.076 & 0.067 & 0.067 \\
\hline \multicolumn{7}{|l|}{ Market orientation } \\
\hline Market access & & & & & 0.131 & 0.122 \\
\hline English readers & & & & & $0.051^{\mathrm{a}}$ & $0.033^{a}$ \\
\hline \multicolumn{7}{|l|}{ Farm experience } \\
\hline Age & & & & & & 0.135 \\
\hline Log-likelihood & 2057.35 & 2086.28 & 2081.49 & 2115.09 & 2130.77 & 2144.02 \\
\hline$\chi^{2}$-Statistic & 110.75 & 166.95 & 154.10 & 178.64 & 199.31 & 202.53 \\
\hline
\end{tabular}

Notes: the standard errors are corrected for possible heteroskedasticity using the White method. All coefficients are statistically significant at the $1 \%$ level unless noted.

a Not statistically significant at the $10 \%$ level. 
Table 4

Truncated regression results-omitting slaveholding households.

\begin{tabular}{|c|c|c|c|c|c|c|}
\hline Variable & (1) & (2) & (3) & $(4)$ & (5) & (6) \\
\hline \multicolumn{7}{|c|}{ Intra-ethnic categories } \\
\hline Full-blood share & -0.157 & -0.100 & & -0.077 & -0.062 & -0.069 \\
\hline All mixed-blood & & & 0.096 & & & \\
\hline Partial mixed & & & 0.029 & & & \\
\hline Married whites & & & 0.091 & & & \\
\hline \multicolumn{7}{|l|}{ Farm size } \\
\hline Land & & 0.012 & 0.016 & 0.017 & 0.016 & 0.016 \\
\hline Land $^{2}$ & & -0.001 & -0.001 & -0.001 & -0.001 & -0.001 \\
\hline \multicolumn{7}{|l|}{ Spatial heterogeneity } \\
\hline Soil quality index & & & & 0.102 & 0.092 & 0.092 \\
\hline \multicolumn{7}{|l|}{ Market orientation } \\
\hline Market access & & & & & 0.108 & 0.097 \\
\hline English readers & & & & & $0.087^{a}$ & $0.066^{\mathrm{a}}$ \\
\hline \multicolumn{7}{|l|}{ Farm experience } \\
\hline Age & & & & & & 0.140 \\
\hline Log-likelihood & 2157.96 & 2285.18 & 2284.72 & 2333.62 & 2345.86 & 2359.67 \\
\hline$\chi^{2}$-Statistic & 63.17 & 201.71 & 200.10 & 225.21 & 246.63 & 252.08 \\
\hline
\end{tabular}

Notes: the standard errors are corrected for possible heteroskedasticity using the White method. All coefficients are statistically significant at the $1 \%$ level unless noted.

a Not statistically significant at the $10 \%$ level.

After recomputing the technical efficiency measures, the regression results for the non-slaveholding households are contained in Table 4. The efficiency difference between mixed-blooded and fullblooded households is still statistically significant but the efficiency differential is now highest in all mixed-blooded households. However, the omission of slaveholders did not affect any estimated relationship between efficiency and the set of exploratory variables. For example, once the slaveholding households are removed, fullblooded households are estimated to be between $6.2 \%$ and $10.0 \%$ less efficient than mixed-blooded households.

Third, the unit of observation is adjusted from households to communities in order to incorporate all the data contained in the census. The aggregation method used here follows from McLoughlin and Conser (1977). Communities are defined by the place-names given in the census and using this technique, $103 \mathrm{com}-$ munities are identified from the census data. Since each community contained at least one full-blooded member, intra-ethnic decompositions cannot be used. Instead, the continuous measure (i.e., the full-blood share in a community) is used. Several models were considered and the results are located in Table 5. On average, com- munities with all full-blooded Cherokees were $7.8 \%$ less efficient than communities with all mixed-blooded members. Productivity differentials decreased once farm size, spatial heterogeneity, market orientation and farm experience were included. There are two possible reasons why the intra-racial variable become insignificant: (1) this ad hoc aggregating technique may not be an accurate way to combine observations; and (2) incorporating unusable observations with zero values for acres cultivated and corn cultivated, especially for slaveholders with 30 or more slaves, may imply heavier reliance on cash crops which would lower their measure of technical efficiency. Regardless, the variable of interest, the fullblood share, reflects a similar negative relationship with efficiency as shown in the earlier models. Therefore, all three tests suggest that it is unlikely that measurement error influenced these results.

\subsection{Post-removal data}

To conduct a direct test of the relative productivity of Cherokee farmers, a sample of Cherokee and white households are taken from the 1850 and 1860 population and agricultural manuscript

Table 5

Truncated regression results-community analysis.

\begin{tabular}{|c|c|c|c|c|c|}
\hline Variable & $(1)$ & $(2)$ & (3) & $(4)$ & (5) \\
\hline \multicolumn{6}{|l|}{ Intra-ethnic categories } \\
\hline Full-blood share & $-0.078^{a}$ & $-0.072^{b}$ & $-0.014^{b}$ & $-0.165^{b}$ & $-0.174^{b}$ \\
\hline \multicolumn{6}{|l|}{ Farm size } \\
\hline lnLand & & $0.009^{b}$ & $0.019^{a}$ & $0.019^{a}$ & $0.019^{\mathrm{a}}$ \\
\hline \multicolumn{6}{|l|}{ Spatial heterogeneity } \\
\hline Soil quality index & & & 0.165 & 0.169 & 0.168 \\
\hline \multicolumn{6}{|l|}{ Market orientation } \\
\hline Market access & & & & $0.002^{b}$ & $0.017^{b}$ \\
\hline English readers & & & & $0.047^{b}$ & $0.04^{b}$ \\
\hline \multicolumn{6}{|l|}{ Farm experience } \\
\hline Age & & & & $0.324^{b}$ & $0.320^{b}$ \\
\hline Log-likelihood & 60.30 & 60.55 & 74.47 & 76.74 & 77.57 \\
\hline$\chi^{2}$-Statistic & $2.17^{b}$ & $2.84^{\mathrm{b}}$ & 15.04 & 21.73 & 22.37 \\
\hline
\end{tabular}

Notes: the standard errors are corrected for possible heteroskedasticity using the White method. All coefficients are statistically significant at the $1 \%$ level unless noted.

a Statistically significant at the $10 \%$ level.

b Not statistically significant at the $10 \%$ level. 
Table 6

Post-removal technical efficiency variables.

\begin{tabular}{|c|c|}
\hline Variable & Definition \\
\hline \multicolumn{2}{|l|}{ Input variables } \\
\hline Farm labor supply ${ }^{a}$ & Number of prime age male equivalents. \\
\hline Land & The number of improved acres on the farm. \\
\hline Livestock & The value of livestock \\
\hline Physical capital & The value of farming implements and machinery. \\
\hline \multicolumn{2}{|l|}{ Output variables } \\
\hline Corn & Bushels of corn harvested. \\
\hline Wheat & Bushels of wheat harvested. \\
\hline Peas and beans & Bushels of peas and beans harvested. \\
\hline Potatoes & Bushels of Irish and sweet potatoes harvested. \\
\hline Oats & Bushels of oats harvested. \\
\hline Tobacco & Pounds of tobacco harvested. \\
\hline Wool & Pounds of wool produced. \\
\hline \multicolumn{2}{|l|}{ Race category } \\
\hline Cherokee & 1 if the household contains Cherokees, 0 otherwise. \\
\hline \multicolumn{2}{|l|}{ Trends } \\
\hline Time & A continuous time trend. \\
\hline \multicolumn{2}{|l|}{ Spatial heterogeneity } \\
\hline Real estate & Value of real estate. \\
\hline
\end{tabular}

a Household members are converted into prime age male equivalents using Fogel and Engerman's (1977) labor weights. In particular, the following weights were used for males: ages $10-14,0.40$; ages $15-19,0.88$; ages $20-54,1.0$; ages $55-59,0.75$. The weights for females were assumed to be $50 \%$ of the male participation rate for each corresponding age category.

censuses. The white population in Haywood County in 1850, which was later incorporated into Jackson County by 1860 , was sampled in small blocks with an interval size of 30 households. These farm households were matched with information in the population schedule to determine the available farm labor supply. All Cherokee households in the agricultural schedules were collected from these 2 census years and matched to information in the population schedules. In sum, there are 271 total households in the sample, comprising of 145 white and 126 Cherokee households. Since the North Carolina Cherokees did not hold slaves, only nonslaveholding white households were left in the sample in order to make valid comparisons. Given the soil fertility and distance to markets, only $2 \%$ of the white sample contained slaveholders, none of whom held over five slaves.

The variables used to measure technical efficiency and to model its determinants are listed in Table 6. The most-commonly listed outputs are selected for the DEA analysis, specifically: corn, wheat, peas and beans, potatoes, oats, tobacco and wool. The census takers also enumerated the number of improved acres, value of farming implements and machinery, and value of livestock, all of which are considered inputs into agricultural production. Most importantly, Fogel and Energman's (1977) labor variable definitions for free labor can be adopted. In particular, the gender and ages of the households are used to compute the prime male labor equivalent for each household. Therefore, seven outputs and four inputs are used to compute the household-level technical efficiency measure.

The second-stage variables include a race dummy variable indicating if the household is comprised of Cherokees. Since there is no information on the intra-racial composition of a Cherokee household, this category cannot be expressed as a continuous variable. However, this community comprised primarily of full-blooded Cherokees (Finger, 1984). The other environmental variables include farm size and a proxy for soil quality, which is the value of real estate. The rationale for using real estate values as a proxy is that once farm size, farm value and efficiency are controlled for, the variation in real estate should be closely related to differences in soil fertility.
Table 7

The determinants of post-removal technical efficiency.

\begin{tabular}{|c|c|c|c|c|}
\hline Variable & $(1)$ & $(2)$ & (3) & $(4)$ \\
\hline \multicolumn{5}{|l|}{ Race category } \\
\hline Cherokee & -0.049 & $-0.041^{a}$ & $-0.007^{c}$ & $-0.006^{c}$ \\
\hline \multicolumn{5}{|l|}{ Trends } \\
\hline Time & & $0.022^{c}$ & $0.019^{c}$ & $0.025^{c}$ \\
\hline \multicolumn{5}{|l|}{ Farm size } \\
\hline Land & & & 0.002 & $0.002^{\mathrm{a}}$ \\
\hline Land $^{2}$ & & & $-0.001^{a}$ & $-0.001^{a}$ \\
\hline \multicolumn{5}{|c|}{ Spatial heterogeneity } \\
\hline Real estate & & & & $0.001^{b}$ \\
\hline Log-likelihood & 126.51 & 126.90 & 130.37 & 131.24 \\
\hline$\chi^{2}$-Statistic & 6.84 & $7.59^{a}$ & 15.88 & 24.71 \\
\hline
\end{tabular}

Notes: the standard errors are corrected for possible heteroskedasticity using the White method. All coefficients are statistically significant at the $1 \%$ level unless noted.

a Statistically significant at the 5\% level.

b Statistically significant at the $10 \%$ level.

c Not statistically significant at the $10 \%$ level.

\subsection{Post-removal results}

Following the method discussed in Section 2, the technical efficiency of each household is estimated and the truncated regressions results are located in Table 7 . The variable of interest is the Cherokee dummy variable. According to model (1), Cherokees were on average only $4.9 \%$ less efficient than their white neighboring households. Since some of the variation in efficiency is due to general changes over time in production techniques, including a time trend into model (2) still generates a negative and significant coefficient on the Cherokee dummy variables. After the data are detrended, the Cherokee farm households were on average $4.1 \%$ less efficient than their neighboring white households.

Once farm size and real estate values are controlled for, models (3) and (4) reveal that the efficiency differential is eliminated between Cherokee and white households. The inverse relationship between efficiency and farm size still holds after removal and the value of real estate is positively related to efficiency. Though not shown here, these general findings are robust to removing potentially influential outliers. In sum, these findings reveal that post-removal Cherokee agriculture performed remarkably well relative to their neighboring whites.

\section{Concluding remarks}

These findings suggest that racial hierarchy was a significant determinant of pre-removal agricultural efficiency. If the desire to maintain traditional farming methods manifested itself into lower efficiency, then this inefficiency could be considered the cost of cultural persistence. The strongest influence of a mixed-blooded family member on technical efficiency occurred when a household contained a married white, who were mostly males. These findings run counter to Perdue $(2003,2004)$ claims that white males had little influence on household behavior. Other factors, such as farm size, market access, and experience, all of which have been universally shown to enhance efficiency, substantially affected Cherokee agricultural efficiency as well.

On the other hand, post-removal Cherokee efficiency in North Carolina was slightly less or equal to the efficiency of their white non-slaveholding neighbors. While there is evidence of Cherokee farm inefficiency, white productivity premiums are not robust across model specifications. The differences between pre- and post-removal efficiency of full-blooded Cherokees suggest that cultural persistence may have been a bigger concern before removal. 
For example, after Cherokee removal, the chief goal of the North Carolina Cherokees was to demonstrate their proclivity towards farming in order to obtain U.S. citizenship (Finger, 1984). This incentive did not exist among pre-removal full-blooded Cherokees who often refused to participate in the government's "civilization" program. This empirical study corroborates with this aspect of Cherokee history.

Future research might determine the robustness of these findings by either adopting a parametric approach or uncovering comparative data on other Southeastern Indians. Census data also exist on postbellum Cherokee agriculture in present-day Oklahoma. These data could help extend the analysis of race and productivity well after removal. Regardless, through the adoption of these data sets, the determinants of Cherokee productive efficiency can at least shed more light on the ongoing debate over the role of race within Southeastern Indian communities.

\section{References}

Champagne, D., 1992. Social Order and Political Change: Constitutional Governments Among the Cherokee, the Choctaw, the Chickasaw, and the Creek. Stanford University Press, Stanford.

Chayanov, A.V., 1966. The Theory of Peasant Economy. R.D. Irwin, Homewood.

Cass, L., 1830. Removal of the Indians. North American Review 30, 62-121.

David, P.A., Temin, P., 1979. Explaining the relative efficiency of slave agriculture in the antebellum South: comment. American Economic Review 69 (1) 213-218.

de Vattel, E., 1758. The Law of Nations or Principles of the Natural Law. Translated by Joseph Chitty, Esq. T. \& J.W. Johnson, Philadelphia.

Dunaway, W., 1997. Rethinking Cherokee acculturation: agrarian capitalism and women's resistance to the cult of domesticity, 1800-1838. American Indian Culture and Research Journal 21 (1), 155-192.

Färe, R., Grooskopf, S., Lovell, C.A.K., 1994. Production Frontiers. Cambridge University Press, Cambridge.

Farrell, M.J., 1957. The measurement of productive efficiency. Journal of the Royal Statistical Society, Series A 120 (3), 253-290.

Field, E.B., 1988. The relative efficiency of slavery revisited: a translog production function approach. American Economic Review 78 (3), 543-549.

Finger, J.R., 1984. The Eastern Band of Cherokees, 1819-1900. The University of Tennessee Press, Knoxville.

Fogel, R.W., Engerman, S.L., 1977. Explaining the relative efficiency of slave agriculture in the antebellum South. American Economic Review 67 (3), 275-296.

Goodwin, G.C., 1977. Cherokees in Transition: A Study of Changing Culture and Environment Prior to 1775. The University of Chicago, Department of Geography Research Paper no. 181, Chicago.

Halliburton Jr., R., 1977. Red Over Black: Black Slavery Among the Cherokee Indians. Greenwood Press, Westport.

Hatley, T., 1988. Cherokee Women Farmers Hold Their Ground. In: Mitchell, R.D.(Ed.) Appalachian Frontiers: Settlements, Society, and Development in the Preindustrial Era. University Press of Kentucky, Lexington.

Hilgard, E.W., 1884. Report on Cotton Production in the United States, Also Embracing Agricultural and Physico-Geographical Descriptions of the Several Cotton States and of California, vol. 2. U.S. Government Printing Office, Washington, DC.

Hudson, C., 1976. The Southeastern Indians. The University of Tennessee Press, Knoxville.
Helfand, S.M., Levine, E.S., 2004. Farm size and the determinants of productivity efficiency in Brazilian Center-West. Agricultural Economics 31, 241 249.

Jackson, A., 1833. Fifth Annual Message to Congress. Government Printing Office Washington.

Litton, G., 1940. Enrollment records of the Eastern band of Cherokee Indians. The North Carolina Historical Review 17 (3), 199-231.

McLoughlin, W.G., 1974. Red Indians, black slavery, and white racism: America's slaveholding Indians. American Quarterly 26 (4), 367-385.

McLoughlin, W.G., 1986. Cherokee Renascence in the New Republic. University of Princeton Press, Princeton.

McLoughlin, W.G., Conser Jr., W.H., 1977. The Cherokee in transition: a statistica analysis of the Federal Cherokee census of 1835. The Journal of American History 64 (3), 678-703.

McLoughlin, W.G., Conser Jr., W.H., 1984. The Cherokee censuses of 1809, 1825, and 1835. In: McLoughlin, W.G. (Ed.), The Cherokee Ghost Dance. Mercer University Press, Macon.

Malone, H.T., 1956. Cherokees of the Old South: A People in Transition. University of Georgia Press, Athens.

Perdue, T., 1979. Slavery and the Evolution of Cherokee Society, 1540-1866. The University of Tennessee Press, Knoxville.

Perdue, T., 2003. "Mixed Blood" Indians: Racial Construction in the Early South. The University of Georgia Press, Athens.

Perdue, T., 2004. Race and culture: writing the ethnohistory of the early south Ethnohistory 51 (4), 701-723.

Perdue, T., Green, M.D., 2007. The Cherokee Nation and the Trail of Tears. Viking Adult, New York

Perry, M.J., 1974. Food Use of "Wild" Plants by Cherokee Indians. Masters Thesis, University of Tennessee, Knoxville.

Robertson, P., 2002. The Power of the Land: Identity, Ethnicity, and Class Among the Oglala Lakota. Routledge, New York.

Royce, C.C., 1975. The Cherokee Nation of Indians. Aldine Publishing Company, Chicago.

Saunt, C., Krauthamer, B., Miles, T., Naylor, C.E., Sturm, C., 2006. Rethinking Race and Culture in the Early South. Ethnohistory 53 (2), 399-405.

Sen, A.K., 1966. Peasants and dualism with or without surplus labor. Journal of Political Economy 74 (5), 425-450.

Shephard, R.W., 1970. Theory of Cost and Production Functions. Princeton University Press, Princeton.

Sherlund, S.M., Barrett, C.B., Adesina, A.A., 2002. Smallholder technical efficiency controlling for environmental production conditions. Journal of Development Economics 69, 85-101.

Simar, L., Wilson, P.W., 2007. Estimation and inference in two-stage semi- parametric models of production processes. Journal of Econometrics 136, 31-63.

Sturm, C., 2002. Blood Politics: Race, Culture, and Identity in the Cherokee Nation of Oklahoma. University of California Press, Berkeley.

Thornton, R., 1990. The Cherokees: A Population History. University of Nebraska Press, Lincoln.

Weiman, D.F. 1987. Farmers and the market in antebellum America: a view from the Georgia upcountry. The Journal of Economic History 47 (3), $627-$ 647.

Weiss, T., 1992. U.S. labor force estimates and economic growth, 1800-1860. In: Gallman, R.E., Wallis, J.J. (Eds.), American Economic Growth and Standards of Living before the Civil War. The University of Chicago Press, Chicago.

White, M.E., 1975. Contemporary use of native plant foods by the Eastern Cherokees Appalachian Journal 2 (4), 323-326.

Wilms, D.C., 1978. Cherokee acculturation and Changing land use practices. The Chronicles of Oklahoma 56 (3), 331-343.

Wishart, D.M., 1995. Evidence of surplus production in the Cherokee Nation prior to removal. The Journal of Economic History 55 (1), 120-138. 